\title{
HARVESTING MYCORRHIZAL FUNGI: DOES IT PUT CALADENIA PLANTS IN PERIL?
}

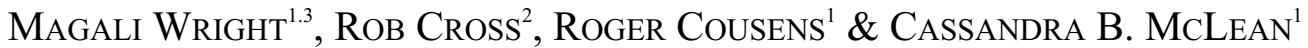 \\ 'School of Resource Management, Burnley Campus, The University of Melbourne, 500 Yarra Boulevard \\ Richmond, Victoria, Australia, 3121 \\ ${ }^{2}$ Royal Botanic Gardens Melbourne, Birdwood Avenue, South Yarra, Victoria 3141 Australia \\ ${ }^{3}$ Author for correspondence: m.wright2@pgrad.unimelb.edu.au
}

KeY WoRDS: mycorrhizal harvesting, isolation, Caladenia, emergence, reproduction

The 'slice' method for harvesting mycorrhizal fungi from terrestrial orchids has been suggested for use with endangered species (Dixon 2004, Stewart 2004). It involves uncovering the mycotrophic region (containing mycorrhizal infection) of a plant and removing a slice of tissue for fungal isolation. This method is less destructive than removing whole mycotrophic parts or whole plants, which are the most common published methods of harvesting orchid mycorrhizal fungi. The 'slice' method is especially useful for Caladenia species, as their mycotrophic tissue occurs in a swollen collar beneath the leaf, which, when removed totally stops photosynthesis and reproduction in a given season. At this stage, there are no published studies using this potentially useful method for harvesting Caladenia mycorrhizal fungi. Lack of evidence to support the use of this technique has limited its application in the symbiotic propagation and conservation of endangered terrestrial orchids. The focus of this study therefore was to examine the effect of the 'slice' method on orchid emergence and reproduction using a relatively common species, Caladenia tentaculata Schltdl.

\section{Preliminary experiment}

A preliminary experiment was undertaken at a C. tentaculata population located near Maldon, Victoria. In 2004, 99 adult plants were marked for monitoring and mycorrhizal fungi was harvested from six of these plants at budding stage (winter) and from ten plants at flowering stage (spring). Tissue slices were collected from each plant by removing soil to $1 \mathrm{~cm}$ below the stem-collar and taking a 2-3 mm slice from the rinsed stem-collar with a sterile scalpel blade. The life stage of each marked plant was recorded in winter (emergent or non-emergent) and again in spring (flowering or non-flowering) for three growing seasons, commencing in 2004. A fungal isolation experiment identified a culture method with a $100 \%$ success rate. This method involved surface sterilising the tissue slices with $0.5 \% \mathrm{NaOCl}$ for 30 seconds and plating fungal pelotons (as in Rasmussen et al. 1990) onto the Fungal Isolating Medium (FIM, Clements et al. 1986) with $0.05 \%$ streptomycin. All isolations were undertaken within 24 hours of harvesting. One fungal isolate from each plant successfully cultured was tested in its ability to germinate $C$. tentcualata seed. All isolates tested germinated seed, thus confirming their mycorrhizal status.

Initial results suggested that the season of harvest affected the subsequent emergence of harvested plants. The 2005 emergence results revealed that significantly more plants from which mycorrhizal fungi were harvested in spring (2004) emerged (100\%) than those harvested in winter $(50 \%)$ of the same year. However, the 2006 emergence results did not support the initial finding as the emergence of the plants harvested at the two time intervals was the same (66\%). In neither year did the emergence of the harvested plants differ significantly from that of the un-harvested plants. This lack of significant differences indicates that harvesting mycorrhiza from Caladenia plants using the 'slice' method does not affect subsequent plant emergence within two years.

\section{Multiple population experimentation}

Adult plants from six geographically distinct $C$. tentaculata populations in Victoria (located near 
Angelsea, Chewton, Inverleigh, and Maldon) were marked for monitoring. Thirty-three plants from the Anglesea population, 30 from the Inverleigh population, 29 from the Chewton population and 83 plants from the Maldon population were marked. In 2005, six adult plants from six populations (including unmonitored populations at Wonthaggi and Eltham) were harvested using the 'slice' method in winter and from the four monitored populations in spring. Half of the harvested plants from each site were hand pollinated and the seed was collected for viability testing, using fluorescein diacetate (FDA) staining. Plants were monitored in winter and spring for two growing seasons. Fungal isolates were successfully obtained from all but one of the 36 plants harvested in winter using the method optimised in the preliminary experiment. At least one isolate from each successfully cultured plant was tested to determine its ability to germinate seed. The germination experiments, part of a large fungal diversity study, confirmed the mycorrhizal status of all but one of 49 isolates.

A proportion of the emergent un-harvested plants at all four populations had died back before the spring monitoring in 2005. These plants lost some photosynthetic and complete reproductive function for the 2005 season. Analysis of the spring 2005 monitoring data revealed a significant difference between the proportion of harvested (44\%) and unharvested $(86 \%)$ plants that remained above ground in the Maldon population. There was no such difference in the three other monitored populations. This indicated that the effect of the 'slice' method within the year of harvest differed between $C$. tentaculata populations. The 2006 emergence results showed no significant difference between plants harvested in winter $(68 \%)$ and those harvested in spring (66\%) supporting the 2006 results of the preliminary experiment. As these results were obtained using a larger sample size across a number of environments, they are more reliable than the initial findings. They clearly show that there is no difference in the effect on emergence between the seasons of harvest.

Emergence of harvested and un-harvested plants did not differ significantly at any of the four monitored populations. This supports the findings of the preliminary experiment and clearly shows that harvesting does not affect the subsequent emergence of Caladenia plants. There was no effect of harvesting on the flowering observed in C. tentaculata populations in this study. The proportions of harvested and un-harvested plants that flowered in the four monitored populations in spring 2005 were not significantly different. Harvesting did not significantly affect seed viability, which was $54 \%$ for harvested plants and 58\% for un-harvested plants across all six populations. Analysis of the spring monitoring and seed viability data suggests that harvesting did not negatively effect reproduction in the year of harvest.

\section{Endangered taxa}

In 2005 mycorrhizal fungi was harvested from single plants of two endangered Caladenia taxa, $C$. sp. aff. fragrantissima (central Victoria) sensu Bishop (1996) and C. sp. aff. fragrantissima (Inverleigh) sensu Ross (2000). The same methodology was used as above. Both harvested plants emerged in 2006. The isolations from both endangered Caladenia taxa were successful and isolates from both taxa were used to germinate seed for ex situ cultivation and re-introduction. All the isolates tested were able to germinate seed from the taxa they were harvested from. These results show that the 'slice' method can be effectively used on endangered Caladenia taxa.

\section{Conclusions}

This study has shown that the 'slice' method of harvesting can be used to successfully isolate mycorrhizal fungi from Caladenia plants. It has also shown that this method can be used both in large fungal diversity studies with common species and to obtain mycorrhiza for the propagation of endangered taxa for direct conservation purposes. Harvesting mycorrhiza using this method does not affect the emergence of Caladenia plants up to two years after harvesting. Initial results suggested that spring harvesting had less affect on subsequent plant emergence than winter harvesting. Further experimentation across multiple C. tentaculata populations revealed that there was no difference in the effect between the two harvesting times. No negative effect of harvesting on reproduc- 
tion of Caladenia plants was recorded. The effect of the 'slice' method on plant function was shown to differ between $C$. tentaculata populations within the year of harvest.

AcKNOwledgments. We would like to acknowledge advice of Dr. Graham Hepworth with statistical analysis. We also acknowledge the generous funding of the Australian Orchid Foundation, the Department of Sustainability and Environment (Victorian Government), the Natural Heritage Trust, the E.A. Crespin Scholarship, the J.M. Higgins Research Foundation and the Melbourne Abroad Travelling Scholarships.

\section{LITERATURE CITED}

Clements, M., P.J. Cribb \& H. Muir. 1986. A preliminary report on the symbiotic germination of European terrestrial orchids. Kew Bull. 14: 437-445.

Dixon, K.W. 2004. Orchid re-introduction workshop, $2^{\text {nd }}$ International Orchid Conservation Congress, Sarasota, Florida.

Rasmussen, H.N., T.F. Andersen \& B. Johansen. 1990. Temperature sensitivity of in vitro germination and seedling development of Dactylorhiza majalis (Orchidaceae) with and without a mycorrhizal fungus. Pl. Cell Environ. 13: 171-177.

Stewart, S.L. 2004. Mycorrhizal workshop, $2^{\text {nd }}$ International Orchid Conservation Congress, Sarasota, Florida.

Magali Wright is a PhD student at the University of Melbourne studying use of mycorrhizal fungi in re-introduction of Caladenia species. She also works at the Royal Botanic Gardens, Melbourne, as an orchid conservation officer.

Rob Cross supervises the ex situ component of the Recovery Plans for Endangered Victorian orchids at the Royal Botanic Gardens, Melbourne in association with the Department of Sustainability and Environment (DSE).

Prof. Roger Cousens is a researcher and lecturer in the field of weed ecology. His main research interests are plant population biology, weed ecology, invasions, terrestrial orchids and the application of ecology to management decisions.

Cassandra McLean is a senior lecturer at the University of Melbourne, Burnley Campus. Her research interests include mycorrhizas of the Ericaceae and Orchidaceae and there use in conservation. 